\title{
Flood Reduction Function of Paddy Rice Fields under Different Water Saving Irrigation Techniques
}

\author{
Joko Sujono \\ Department of Civil and Environmental Engineering, Faculty of Engineering, Gadjah Mada University, \\ Yogyakarta, Indonesia \\ E-mail:jsujono@tsipil.ugm.ac.id,jsujono@yahoo.com \\ Received March 9, 2010; revised April 11, 2010; accepted May 4, 2010
}

\begin{abstract}
This study is conducted to investigate the function of paddy fields for flood reduction under different water saving irrigation techniques. A daily water balance component data including rainfall, percolation, and overflow through the paddy field levee were collected from experimental paddy rice fields during rainy season cultivation. Results show that paddy field was very effective in flood reduction. More than $40 \%$ of rainfall could be stored in the paddy fields. However, the effectiveness of paddy fields in flood reduction was highly depends on the WSI technique used. Semi dry cultivation technique was the most effective one in terms of flood reduction. It retained the rainfall up to $55.7 \%(365 \mathrm{~mm})$ of the total rainfall $(636 \mathrm{~mm})$ without reducing the yield. In terms of flood volume reduction, the alternate wetting and drying performed similarly with traditional continuous flooding, i.e., $37.2 \%$ and $40.8 \%$, respectively.
\end{abstract}

Keywords: Flood Reduction Function, Water Saving Irrigation, Paddy Field

\section{Introduction}

Paddy rice cultivation with paddy field irrigation has multi-functional roles not only to provide food securely but also to maintain other functions such as economic, culture and environment [1-3]. One of the important functions related to environment issues is flood prevention and water conservation. A number of studies of these functions have been carried out mainly in Japan from the early 1980s. The studies described the functions of paddy fields to increase the water storage capacity of river basins, lower the peak flow of rivers, and increase groundwater recharge [2].

Recently, a number of studies have been done to investigate the function of paddy fields in storing rainfall water [3-6]. Unami and Kawachi [4] studied a flood simulation method to investigate the effect of irrigation tanks and paddy fields in flood reduction of drainage canals. It is easy to understand the function of paddy fields in detaining floods in their field systems as they temporary store rainfall. Kim et al. [5] mentioned that the paddy field has a flood reduction function more scattered compared with dam. The large amount of water stored in paddy fields has a function as many small reservoirs or dams [3]. Kim et al. [6] developed a daily paddy water balance model at two field experimental locations. The study indicated that on average the amount of paddy storage during flood period is $333 \mathrm{~mm}$ to rainfall ranging from $425 \mathrm{~mm}$ to $851 \mathrm{~mm}$. Sujono [7] mentioned that flood routing analysis indicated that paddy fields is also very effective in flood reduction both flood peak and volume. This paper presents the effect of water irrigation management technique used in the paddy rice cultivation on flood reduction.

\section{Water Saving Irrigation}

Traditionally, a lot of water is needed for the paddy rice growing, since rice is grown under continuously flooded condition in paddy fields except for a short period of sun drying at the late stage of rice tiller [8]. The method has also been reported only yields a low of rice or low water productivity [9]. There is a major challenge for paddy rice cultivators to increase the productivity of water used to grow rice. To grow rice with much less water in the scarce water condition due to increasing demand of water for domestic and industry is necessary and possible [10]. Efforts have been conducted to increase the water productivity for growing rice $[8,10,11]$. 
The formal research on water saving irrigation (WSI) techniques for rice in China was started around 1985. The impetus came from different aspects such as shortages of food, electricity and water demand for industrial, domestic increased sharply. The research on improvement of water management for paddy rice was given priority for funding from the Government [9]. Since then, a number of WSI techniques in China have been studied $[9,12]$. Recently, another WSI technique, called the system of rice intensification (SRI) has been attracting more attention following the reports of its dramatic yield and water productivity advantages in Madagascar. Among the available WSI techniques are presented as the following.

\subsection{System of Rice Intensification}

The SRI technique has been evaluated at a number of countries outside Madagascar. Great results of the SRI practice have been reported $[13,14]$. In Sri Lanka, a team of IWMI researchers surveyed 60 farmers using the SRI method and 60 farmers not using it, randomly selected in two districts. There was a $44 \%$ increase in yield/ha and that water productivity was increase by $90 \%$ [13]). In Indonesia, Nippon Koei [14] has promoted the SRI practice in eastern Indonesia, i.e., South Sulawesi and West Nusa Tenggara provinces. By using the SRI method, the yield are $9.5 \mathrm{t} / \mathrm{ha}$. It was increase by $93 \%$ compare with non SRI yields of $4.9 \mathrm{t} / \mathrm{ha}$. Water saving with the SRI is 40\%. McDonald et al. [15] compiled a database of experiments where SRI was evaluated against accepted best management practices (BMP). Among 40 experimental reports/papers that applying SRI, five from Madagascar and the others from Asian countries, there was no evidence outside of Madagascar that SRI produced remarkable yield when compared to the accepted BMP.

\subsection{Alternate Wetting and Drying}

The alternate wetting and drying (AWD) has spread and widely practiced in China [16]. By 2002 the AWD irrigation technique was applied in $40 \%$ of the rice production areas or 12 million ha in China [8]. The AWD practice increases the water productivity on-farm level remarkable up to $1.52 \mathrm{~kg} / \mathrm{m}^{3}$ of water compare with the traditional one, i.e., $1.04 \mathrm{~kg} / \mathrm{m}^{3}$ of water on average in the four provinces in China [9]. The AWD increased the water productivity by $46 \%$ and grain yield marginally by $6 \%$ compared to traditional method. Application the AWD in Tuanlin Irrigation Experimental Station from 1991 to 2000 showed that the yield difference between the AWD and the traditional method was not statistically significant. However, under the AWD the water productivity was much higher (average $27 \%$ ) than under the traditional practice [16].

\subsection{Semi-dry Cultivation}

Comparing the SRI and AWD, semi-dry cultivation (SDC) is the most high water efficiency. The water productivity could reach $70 \%$ higher than traditional method whereas the yield could increase by $9 \%$. SDC can be used in different soils, and it deserves further studying and spreading due to high water use efficiency, beneficial environmental impact and high yield [9].

\section{Materials and Methods}

\subsection{Study Location}

The research was carried out at the Environmental Engineering Laboratory, Department of Civil and Environmental Engineering, Faculty of Engineering, Gadjah Mada University, Yogyakarta, Indonesia. The paddy plot consists of 5 blocks with equal size, i.e., $2 \mathrm{~m} \times 3 \mathrm{~m}$ and $0.8 \mathrm{~m}$ depth, as shown in Figure 1.

The paddy plots were constructed as impermeable as possible to avoid leakage and percolation water flow out from the plots. At the bottom of the plot, a porous pipe $(\Phi 10 \mathrm{~cm})$ was installed to collect the percolation water. The pipe was connected with a tap, so that the percolation water can be measured from outside the plot. To store water used for water irrigation, a small storage was

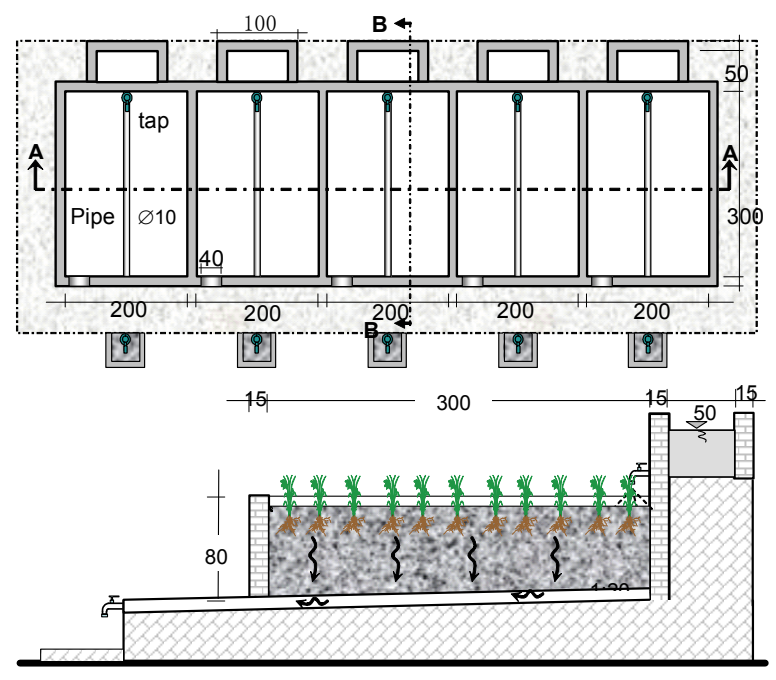

Section B-B

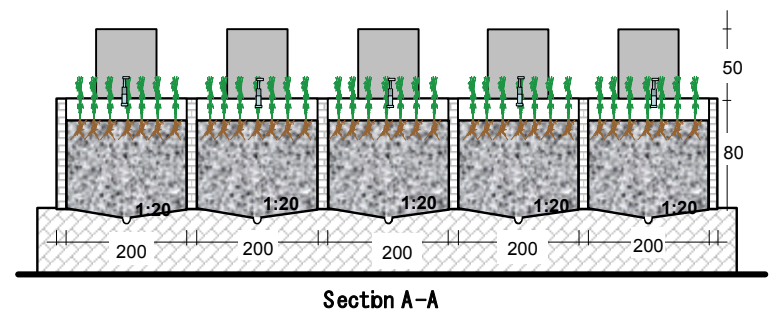

Figure 1. Experimental plots. 
also constructed. In addition, pan-evaporation and rainfall gage were installed near the plots. The research was done from March 2007 until mid of June 2007 starting from land preparation up to harvesting.

\subsection{Paddy Rice Cultivation}

Paddy rice called IR-64 variety was selected for the experiments. This variety was released in 1986, a medium duration variety (100-115 days). Transplanting rice in plots was done following the SRI method, i.e., young seedling (10 days) and wide spacing $(25 \mathrm{~cm} \times 25 \mathrm{~cm})$.

\subsection{Nutrient Control}

Following the guideline from Nippon Koei [14] fertilizer was applied three times as follows: 1) first fertilizer at rate of $125 \mathrm{~kg}$ Urea/ha, $100 \mathrm{~kg}$ SP36/ha and $25 \mathrm{~kg}$ $\mathrm{KCl} /$ ha was given at $7 \mathrm{DAT}$ (days after transplanting); 2) second fertilizer was applied at 25 DAT using $125 \mathrm{~kg}$ Urea/ha and 3) last fertilizer as a top dressing was given at $40 \mathrm{DAT}$ using $100 \mathrm{~kg} \mathrm{ZA/ha.}$

\subsection{Water Management Technique}

Four water management irrigation techniques namely traditional continuous flooding (TRI), SRI, AWD and SDC were applied in the research as shown in Figure 2.

The amount of water and when it should be irrigated vary among the techniques. In the TRI, after transplanting the standing water depth in paddy plot was kept at 30
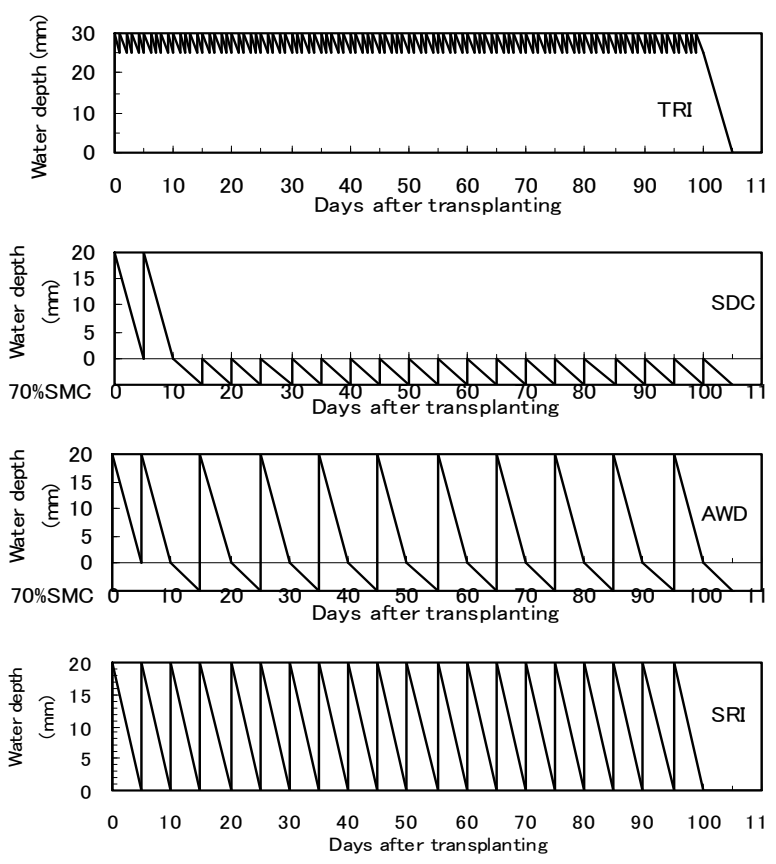

Figure 2. Water management irrigation technique. mm depth. For all the WSI techniques, except the SDC, the upper limit water depth in the plot was $2 \mathrm{~cm}$. There was no water depth on paddy field under the SDC technique after $10 \mathrm{DAT}$. The minimum water depth was set up at $70 \%$ soil moisture capacity (SMC) for the AWD and SDC, whereas for the SRI the minimum was at 0 $\mathrm{mm}$ depth. The extra limit levels for all water management techniques used were set up to $8 \mathrm{~cm}$ for storing more rainfall and spill occurred when the water level goes beyond the extra limit level. When the depth of water in the plot or average moisture content in the root zone falls to the lower limit level, the plot was filled to the upper limit level by irrigation.

\section{Results and Discussion}

\subsection{Effects of Water management Technique on Yield}

Table 1 shows the effect of water management technique on yield. The maximum rice production was obtained under SDC technique with $2.06 \mathrm{~kg} / 6 \mathrm{~m}^{2}$ (3.43 ton/ha) followed by AWD with $1.83 \mathrm{~kg} / 6 \mathrm{~m}^{2}$ (3.05 ton/Ha). The production reduced almost $50 \%$ compared with dry season cultivation [17]. The lower production was affected by lower number of tillers due to high rainfall intensity during growing period. The average productive tiller for all the water management studied was only 12-15 tillers for each hill. During growing period, rainfall almost occurred every day and up to 40 DAT the amount of rainfall was $572 \mathrm{~mm}$ as shown in Figure 3.

\subsection{Effects of Water management Technique on Irrigated Water}

Irrigated water requirement varied depending on WSI

Table 1. Yield production during rainy season cultivation.

\begin{tabular}{ccc}
\hline $\begin{array}{c}\text { Water management } \\
\text { technique }\end{array}$ & Yield (ton/ha) & $\begin{array}{c}\text { \% difference to } \\
\text { control }\end{array}$ \\
\hline TRI (control) & 1.53 & 0 \\
AWD & 3.05 & 99.3 \\
SDC & 3.43 & 125.2 \\
SRI & 2.02 & 32.2 \\
\hline
\end{tabular}

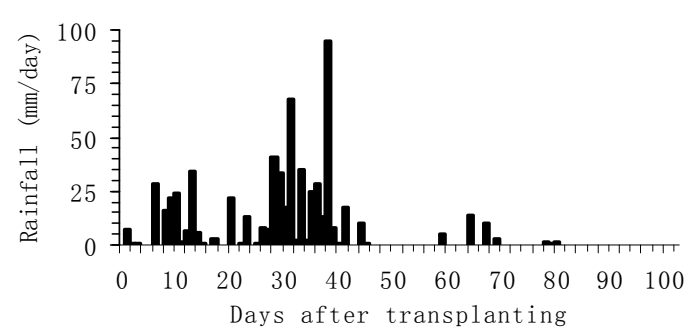

Figure 3. Rainfall during paddy rice cultivation. 
technique used as presented in Table 2. The amount of irrigated water needed during rainy season cultivation was much less than dry season cultivation that required $885 \mathrm{~mm}$ for TRI, $735 \mathrm{~mm}$ for AWD, and $631 \mathrm{~mm}$ for SDC [17]. This condition might be happened due to high rainfall occurred during rainy season cultivation (635 $\mathrm{mm}$ ), whereas at dry season cultivation there was no rainfall at all. The table shows that WSI techniques reduce significantly the amount of water needed for paddy rice cultivation compared to TRI. Using SDC and AWD techniques, the irrigated water reduction reached $55.4 \%$ and $38.5 \%$, respectively. The SRI technique seems required much water due to leakage occurred during the experiment as indicated with much higher percolation $(384 \mathrm{~mm})$ than others.

\subsection{Effects of Water management Technique on Flood Reduction}

Flood reduction under different water irrigation techniques were given at Table 3. The table shows that paddy field (plot) was very effective in storing rainfall in the paddy field and it has a potential function for flood reduction both volume and peak. Flood reduction of paddy plots varied among the water management techniques in the range between $37.2 \%$ up to $55.7 \%$. The SDC technique was the most effective one in flood reduction that retained rainfall at the paddy field up to $55.7 \%$. This phenomenon occurred due to the upper limit of water depth at the plots was kept at $0 \mathrm{~mm}$, whereas for the other techniques such as AWD and SRI the maxi-

Table 2. Water parameters during rainy season cultivation.

\begin{tabular}{|c|c|c|c|c|}
\hline \multirow{2}{*}{ Water parameters } & \multicolumn{4}{|c|}{ Water management technique } \\
\hline & TRI & AWD & SDC & SRI \\
\hline (1) irrigated water $(\mathrm{mm})$ & 194 & 119 & 128 & $319^{*}$ \\
\hline (2) rainfall $(\mathrm{mm})$ & 536 & 635 & 635 & 635 \\
\hline (3) percolation (mm) & 215 & 154 & 156 & $384^{*}$ \\
\hline (4) spill (mm) & 318 & 399 & 282 & 320 \\
\hline $\begin{array}{l}\% \text { irrigated water compared to } \\
\text { control }\end{array}$ & 0 & -38.5 & -55.4 & $97.0^{*}$ \\
\hline
\end{tabular}

Table 3. Flood reduction under different water management technique.

\begin{tabular}{lccccc}
\hline \multirow{2}{*}{ Time } & Rainfall & \multicolumn{5}{c}{ Spill over the plots $(\mathbf{m m})$} \\
\cline { 2 - 6 } & $\mathbf{( m m )}$ & TRI & AWD & SDC & SRI \\
\hline 6-26 April 2007 & 332 & 292 & 302 & 254 & 262 \\
\% reduction & & -12.1 & -9 & -23.6 & -21.2 \\
1 season & 635 & 318 & 399 & 282 & 320 \\
\% reduction & & -40.8 & -37.2 & -55.7 & -49.7 \\
\hline
\end{tabular}

mum water depth was maintained at $2 \mathrm{~cm}$. It means the storage capacity of paddy field for storing rainfall using the SDC technique was higher than other techniques.

\section{Conclusions}

Three water saving irrigation (WSI) management techniques, i.e., alternate wetting and drying (AWD), semi dry cultivation (SDC) and system of rice intensification (SRI) for paddy rice cultivation and traditional continuous flooding (TRI) were applied in the experimental paddy plots. Some important results are summarized as follows.

- Paddy fields were very effective in flood reduction/ retaining rainfall. Flood reduction of paddy plots varies among the water management techniques used in the range between $37.2 \%$ up to $55.7 \%$. The semidry cultivation technique was the most effective one in flood reduction that retained rainfall up to $55.7 \%$.

- Based on the experiment, to increase the function of paddy fields for flood reduction the semi-dry cultivation technique should be applied for paddy rice cultivation especially during rainy season.

- The amount of irrigated water during rainy season cultivation varies among the water management techniques in the range of $128 \mathrm{~mm}$ to $195 \mathrm{~mm}$. It means that rainfall was fully utilized or higher effective rainfall was obtained under WSI without hindering rice production.

- Study on the effectiveness of water saving irrigation techniques on flood reduction at basin scale may be needed to get the whole picture performance of the techniques.

\section{Acknowledgements}

This research was supported by Faculty of Engineering, Gadjah Mada University. The author thanks the students for field work and data collection.

\section{References}

[1] J. W. Ahn, "Rice Farming and Strategy to Rural Development," Paddy and Water Environment, Vol. 3, No. 2, 2005, pp. 73-77.

[2] Y. K Matsuno, K. Nakamura, T. Masumoto, H. Matsui, T. Kato and Y. Sato, "Prospects for Multi-Functionality of Paddy Rice Cultivation in Japan and Other Countries in Monsoon Asia," Paddy and Water Environment, Vol. 4, No. 4, 2006, pp. 189-197.

[3] C. C. Huang, M. H. Tsai, W. T. Lin, Y. F. Ho and C. H. Tan, "Multifunctionality of Paddy Fields in Taiwan," Paddy and Water Environment, Vol. 4, No. 4, 2006, pp. 199-204.

[4] K. Unami and T. Kawachi, "Systematic Assessment of Flood Mitigation in a Tank Irrigated Paddy Fields Area," 
Paddy and Water Environment, Vol. 3, No. 4, 2005, pp. 191-199.

[5] T. C. Kim, U. S. Gim, J. S. Kim and D. S. Kim, "The Multi-Functionality of Paddy Farming in Korea," Paddy and Water Environment, Vol. 4, No. 4, 2006, pp. 169179.

[6] S. J. Kim, G. A. Park and H. J. Kwon, "Evaluation of Paddy Water Storage Dynamics during Flood Period in South Korea," Water Engineering, Vol. 11, No. 5, 2007, pp. 269-276.

[7] J. Sujono, "Water Saving Irrigation on Paddy Fields for Increasing Productivity and for Flood Reduction," IASTED International Conference on Water Resources Management, Hawaii, 2007.

[8] Y. Li and R. Barker, "Increasing Water Productivity for Paddy Irrigation in China," Paddy and Water Environmental, Vol. 2, No. 4, 2004, pp. 187-193.

[9] M. Zhi, "Water Efficient Irrigation and Environmentally Sustainable Irrigated Rice Production in China," International Commission on Irrigation and Drainage, 2002. http://www.icid.org/wat_mao.pdf

[10] F. Rijsberman, "Growing more Rice with less Water," Paddy and Water Environmental, Vol. 2, No. 4, 2004, pp. 181-183.

[11] R. Barker, T. P. Tuong, Y. Li, E. G. Castillo and B. A. M.
Bouman, "Growing more Rice with less Water: Research Findings from a Study in China," Paddy and Water Environmental, Vol. 2, 2004, pp. 185-194.

[12] Y. Li, "Water Saving Irrigation in China," Irrigation and Drainage, Vol. 55, No. 3, 2006, pp. 327-336.

[13] R. E. Namara, P. Weligamage and R. Barker, "Prospects for Adopting System of Rice Intensification in Sri Lanka: A Socio-Economics Assessment," Research Report 75, International Water Management Institute, Colombo, 2003.

[14] N. Koei, "The System of Rice Intensification in East Indonesia,” Nippon Koei Co., Ltd., Nippon Koei, 2005.

[15] A. J. McDonald, P. R. Hobbs and S. J. Riha, "Does the System of Rice Intensification Outperform Conventional Best Management? A Synopsis of the Empirical Record," Field Crops Research, Vol. 96, No. 1, 2006, pp. 31-36.

[16] B. Dong, R. Loeve, Y. H. Li, C. D. Chen, L. Deng and D. Molden, "Water Productivity in the Zhanghe Irrigation System: Issues of Scale," Proceedings of an International Workshop on Water Saving Irrigation for Rice, Wuhan, 2001, pp. 97-115.

[17] J. Sujono, F. Nurrochmad and R. Jayadi, "Growing more Rice with less Water," Research Report, Department of Civil and Environmental Engineering, Faculty of Engineering, Gadjah Mada University, Gadjah Mada, 2006. 